\title{
Production and cross-feeding of nitrite within Prochlorococcus populations
}

Paul M. Berube ${ }^{1, *}$, Tyler O’Keefe ${ }^{1, *}$, Anna Rasmussen ${ }^{1, \#}$, Sallie W. Chisholm ${ }^{1,2, *}$

${ }^{1}$ Department of Civil and Environmental Engineering, Massachusetts Institute of Technology, Cambridge, MA 02139, USA

${ }^{2}$ Department of Biology, Massachusetts Institute of Technology, Cambridge, MA 02139, USA

$\$$ Present address: Department of Earth, Marine, and Environmental Sciences, University of North Carolina at Chapel Hill, Chapel Hill, NC, 27514, USA

\# Present address: Department of Earth System Science, Stanford University, Palo Alto, CA 94305, USA

*Correspondence: pmberube@mit.edu or chisholm@mit.edu

Keywords: Prochlorococcus, Synechococcus, primary nitrite maximum, incomplete nitrate reduction, nitrogen cycle, cross-feeding 


\section{ABSTRACT}

Prochlorococcus is an abundant photosynthetic bacterium in the oligotrophic open ocean where nitrogen $(\mathrm{N})$ often limits the growth of phytoplankton. Prochlorococcus has evolved into multiple phylogenetic clades of high-light (HL) adapted and low-light (LL) adapted cells. Within these clades, cells encode a variety of $\mathrm{N}$ assimilation traits that are differentially distributed among members of the population. Among these traits, nitrate $\left(\mathrm{NO}_{3}{ }^{-}\right)$assimilation is generally restricted to a few clades of high-light adapted cells (the HLI, HLII, and HLVI clades) and a single clade of low-light adapted cells (the LLI clade). Most, if not all, cells belonging to the LLI clade have the ability to assimilate nitrite $\left(\mathrm{NO}_{2}{ }^{-}\right)$, with a subset of this clade capable of assimilating both $\mathrm{NO}_{3}{ }^{-}$and $\mathrm{NO}_{2}{ }^{-}$. Cells belonging to the LLI clade are maximally abundant at the top of the nitracline and near the primary $\mathrm{NO}_{2}^{-}$maximum layer. In some ecosystems, this peak in $\mathrm{NO}_{2}^{-}$concentration may be a consequence of incomplete assimilatory $\mathrm{NO}_{3}{ }^{-}$reduction by phytoplankton. This phenomenon is characterized by a bottleneck in the downstream half of the $\mathrm{NO}_{3}{ }^{-}$assimilation pathway and the concomitant accumulation and release of $\mathrm{NO}_{2}{ }^{-}$by phytoplankton cells. Given the association between LLI Prochlorococcus and the primary $\mathrm{NO}_{2}^{-}$ maximum layer, we hypothesized that some Prochlorococcus exhibit incomplete assimilatory $\mathrm{NO}_{3}{ }^{-}$reduction. To assess this, we monitored $\mathrm{NO}_{2}{ }^{-}$accumulation in batch culture for 3 Prochlorococcus strains (MIT0915, MIT0917, and SB) and 2 Synechococcus strains (WH8102 and WH7803) when grown on $\mathrm{NO}_{3}{ }^{-}$as the sole $\mathrm{N}$ source. Only MIT0917 and SB accumulated external $\mathrm{NO}_{2}{ }^{-}$during growth on $\mathrm{NO}_{3}{ }^{-}$. Approximately $20-30 \%$ of the $\mathrm{NO}_{3}{ }^{-}$transported into the cell by MIT0917 was released as $\mathrm{NO}_{2}^{-}$, with the balance assimilated into biomass. We further observed that co-cultures using $\mathrm{NO}_{3}{ }^{-}$as the sole $\mathrm{N}$ source could be established for MIT0917 and a Prochlorococcus strain that can assimilate $\mathrm{NO}_{2}{ }^{-}$but not $\mathrm{NO}_{3}{ }^{-}$. In these co-cultures, the $\mathrm{NO}_{2}{ }^{-}$ released by MIT0917 was efficiently consumed by its partner strain during balanced exponential growth. Our findings highlight the potential for emergent metabolic partnerships within Prochlorococcus populations that are mediated by the production and consumption of the $\mathrm{N}$ cycle intermediate, $\mathrm{NO}_{2}{ }^{-}$. 


\section{SIGNIFICANCE}

Earth's biogeochemical cycles are substantially driven by microorganisms and their interactions. Given that $\mathrm{N}$ often limits marine photosynthesis, we investigated the potential for $\mathrm{N}$ crossfeeding within populations of Prochlorococcus, the numerically dominant photosynthetic cell in the subtropical open ocean. During growth on $\mathrm{NO}_{3}{ }^{-}$, some Prochlorococcus cells release up to $30 \%$ of their $\mathrm{N}$ uptake as extracellular $\mathrm{NO}_{2}^{-}$. In the wild, Prochlorococcus populations are composed of multiple functional types, including those that cannot use $\mathrm{NO}_{3}{ }^{-}$but can still assimilate $\mathrm{NO}_{2}^{-}$. We show that metabolic dependencies arise when Prochlorococcus strains with complementary $\mathrm{NO}_{2}^{-}$production and consumption phenotypes are grown together on $\mathrm{NO}_{3}{ }^{-}$. These findings demonstrate the potential for emergent metabolic partnerships, possibly modulating ocean nutrient gradients, that are mediated by cross-feeding of $\mathrm{N}$ cycle intermediates.

\section{INTRODUCTION}

Prochlorococcus and its close relative, Synechococcus, are globally abundant cyanobacteria that are jointly responsible for approximately $25 \%$ of marine net primary production - roughly 12 gigatons of fixed carbon each year [1]. The share of marine primary production attributed to Prochlorococcus is predicted to increase over the course of this century as a consequence of a warmer and more stratified ocean $[1,2]$. Phytoplankton growth, and thus primary production, is limited by $\mathrm{N}$ across much of the surface ocean [3]. Given the numerical dominance of Prochlorococcus, examining its genotypic and phenotypic diversity in the context of the $\mathrm{N}$ cycle can inform our understanding of Prochlorococcus' role in marine primary production.

Prochlorococcus has multiple $\mathrm{N}$ assimilation traits, most of which are distributed across cells in Prochlorococcus populations. All Prochlorococcus appear capable of assimilating ammonium $\left(\mathrm{NH}_{4}{ }^{+}\right)$, generally the preferred $\mathrm{N}$ source for cyanobacteria since it is readily incorporated into the amino acid pool [4]. Some Prochlorococcus also contain flexible genes - found in some, but not all genomes - that enable the assimilation of organic $\mathrm{N}$ sources such as urea, cyanate, and amino acids $[5,6,7]$ as well as the inorganic $\mathrm{N}$ sources, $\mathrm{NO}_{3}{ }^{-}$and $\mathrm{NO}_{2}{ }^{-}[8,9,10,11]$. $\mathrm{NO}_{3}{ }^{-}$ assimilation by Prochlorococcus was identified decades after the first strain of Prochlorococcus was brought into culture $[8,9,12]$ - prior to this discovery, it was thought that Prochlorococcus lacked this functional trait because isolated cultures could not use $\mathrm{NO}_{3}{ }^{-}$as a $\mathrm{N}$ source and $\mathrm{NO}_{3}{ }^{-}$ 
assimilation genes were absent among the first sequenced genomes $[6,13]$. It is now evident that there is extensive variability with respect to the $\mathrm{N}$ assimilation traits harbored by

Prochlorococcus. These biological features have the potential to impact $\mathrm{N}$ cycling across the vast subtropical ocean gyres - the consequences of which are not well constrained.

The evolutionary history of $\mathrm{NO}_{3}{ }^{-}$assimilation in Prochlorococcus has deepened our understanding of the selective pressures operating on this organism. It appears likely that the $\mathrm{NO}_{3}{ }^{-}$assimilation gene cluster has been present in Prochlorococcus since their divergence from Synechococcus, but only retained in a subset of more recently emerged clades [11]. While loss of the $\mathrm{NO}_{3}{ }^{-}$assimilation trait has essentially run to completion in most low-light adapted clades, the trait has been retained in a monophyletic group of high-light adapted clades as well as the LLI clade [11]. High-light adapted cells with $\mathrm{NO}_{3}{ }^{-}$assimilation genes appear to be selected for in the surface waters of N-limited systems [10]. In contrast, selection for LLI Prochlorococcus cells with the capacity to assimilate $\mathrm{NO}_{3}{ }^{-}$is not well resolved. This group of Prochlorococcus is widely distributed and abundant, often exceeding the combined depth-integrated abundance of other low-light adapted Prochlorococcus $[14,15]$. LLI cells tolerate extreme fluctuations in light intensity allowing them to survive in surface waters where most low-light adapted Prochlorococcus are essentially absent $[15,16]$. Cells belonging to the LLI clade typically have highest cell abundances in the subsurface chlorophyll maximum layer where nutrient concentrations are higher than the mixed layer $[17,18]$. Intriguingly, we observed a spatial relationship between LLI cells with the $\mathrm{NO}_{3}{ }^{-}$assimilation trait and a peak in $\mathrm{NO}_{2}{ }^{-}$concentration in the water column [10].

In stratified marine systems, elevated concentrations of $\mathrm{NO}_{2}^{-}$in the mid-euphotic zone are ubiquitous. This feature, the primary $\mathrm{NO}_{2}{ }^{-}$maximum layer, is thought to arise from distinct biological processes - either decoupled nitrification or incomplete $\mathrm{NO}_{3}{ }^{-}$reduction by phytoplankton [19]. The respective activities of ammonia-oxidizing and nitrite-oxidizing microorganisms - performing the sequential reactions of nitrification - could drive the accumulation of $\mathrm{NO}_{2}{ }^{-}$in the mid-euphotic zone because of physiological and physiochemical differences related to photoinhibition [20] or cell size and redox chemistry [21]. Alternatively, phytoplankton can be subject to multiple factors affecting the degree to which they excrete $\mathrm{NO}_{2}{ }^{-}$ during growth on $\mathrm{NO}_{3}{ }^{-}$[22]. These factors include light [23], growth rate [24], temperature [25], external $\mathrm{NO}_{3}{ }^{-}$concentration [26, 27, 28], Fe limitation [29], and $\mathrm{N}$ deficiency [26, 30]. 
Several features of Prochlorococcus' diversity suggest that $\mathrm{NO}_{2}^{-}$cycling could be an important facet of this organism's ecology, particularly for the abundant low-light adapted

Prochlorococcus that dominate the upper reaches of the nitracline. In N-limited systems, a sizable fraction (20-50\%) of Prochlorococcus have the capacity for $\mathrm{NO}_{3}{ }^{-}$assimilation [10]. Within the low-light adapted LLI clade of Prochlorococcus, the $\mathrm{NO}_{2}{ }^{-}$assimilation trait appears to be found in most or all cells while the full pathway for $\mathrm{NO}_{3}{ }^{-}$assimilation is only observed in a subset of cells [11]. These trait frequencies bear the hallmarks of medium- frequency dependent selection which are often governed by cross-feeding interactions [31]. Given that LLI Prochlorococcus live in the vicinity of the primary $\mathrm{NO}_{2}^{-}$maximum layer, we hypothesized that those capable of $\mathrm{NO}_{3}{ }^{-}$assimilation have the potential for releasing $\mathrm{NO}_{2}{ }^{-}$back into the environment - consistent with what is observed in larger size classes of phytoplankton [22]. In this study, we explore incomplete assimilatory $\mathrm{NO}_{3}{ }^{-}$reduction by Prochlorococcus and further examine the potential for cross-feeding and intra-population cycling of $\mathrm{NO}_{2}^{-}$, a central intermediate in the $\mathrm{N}$ cycle.

\section{MATERIALS AND METHODS}

Strains. The cultures used in this study included the low-light adapted Prochlorococcus strains MIT0915, MIT0917, and MIT1214, the high-light adapted Prochlorococcus strain SB, as well as Synechococcus strains WH8102 and WH7803 (Table S1). All strains were routinely assayed for heterotrophic contaminants by staining cells with SYBR green and assessing the fluorescence and light scattering properties of both stained and unstained cells using a Guava easyCyte 12HT Flow Cytometer (MilliporeSigma, Burlington, MA, USA) - cultures that did not exhibit the presence of non-photosynthetic cells in the stained samples and had a single cyanobacteria population were presumed axenic and unialgal. All axenic cultures were routinely assessed for purity by confirming a lack of turbidity after inoculation into a panel of purity test broths as described previously [9].

$\mathrm{NO}_{2}{ }^{-}$production rates. The $\mathrm{NO}_{3}{ }^{-}$assimilating strains (MIT0915, MIT0917, SB, WH7803, and WH8102) were grown in triplicate as pure cultures using Pro99 medium (natural seawater base; Sargasso Seawater) with the $800 \mu \mathrm{M}$ ammonium chloride $\left(\mathrm{NH}_{4} \mathrm{Cl}\right)$ omitted and replaced by 800 $\mu \mathrm{M}$ sodium nitrate $\left(\mathrm{NaNO}_{3}\right)$. The cultures were grown in $35 \mathrm{~mL}$ of medium in borosilicate glass 
culture tubes at a temperature of $24^{\circ} \mathrm{C}$ and under continuous illumination from white fluorescent lamps at intensities of $6,36,52$, and $85 \mu \mathrm{mol}$ photons $\mathrm{m}^{-2} \mathrm{~s}^{-1}$. The LLI strains (MIT0915 and MIT0917) had poor and inconsistent growth at the highest light intensity, so these strains were only examined at the 3 lower light intensities $\left(6,36\right.$, and $52 \mu \mathrm{mol}$ photons $\left.\mathrm{m}^{-2} \mathrm{~s}^{-1}\right)$. The Synechococcus strains (WH7803 and WH8102) were only examined at 36, 52, and $85 \mu \mathrm{mol}$ photons $\mathrm{m}^{-2} \mathrm{~s}^{-1}$. Cultures were monitored daily by removing $0.5 \mathrm{~mL}$ of culture in order to determine cell abundances with flow cytometry and $\mathrm{NO}_{2}{ }^{-}$concentrations with the Griess colorimetric method (Supplementary Materials and Methods). Net cell-specific $\mathrm{NO}_{2}^{-}$production rates were calculated as the change in $\mathrm{NO}_{2}{ }^{-}$concentration relative to the logarithmic mean of cell concentrations - to account for exponential growth - for successive time points during the loglinear portion of the growth curve.

Experimental populations. MIT1214 was co-cultured, in triplicate, with either MIT0915 or MIT0917 in $35 \mathrm{~mL}$ of medium in borosilicate glass culture tubes using $\mathrm{NO}_{3}{ }^{-}$as the sole $\mathrm{N}$ source at $24^{\circ} \mathrm{C}$ and $16 \mu \mathrm{mol}$ photons $\mathrm{m}^{-2} \mathrm{~s}^{-1}$ of blue light to simulate the conditions under which these cells would coexist in the wild. As controls, all strains were grown as pure cultures, in duplicate, under the same temperature and light conditions. The MIT1214-MIT0915 and MIT1214MIT0917 co-cultures, as well as the MIT0915 and MIT0917 pure cultures, used Pro99 medium (natural seawater base; Sargasso Seawater) with $800 \mu \mathrm{M}$ sodium nitrate $\left(\mathrm{NaNO}_{3}\right)$ as the sole $\mathrm{N}$ source. Pure cultures of MIT1214 were grown in Pro99 medium using $100 \mu \mathrm{M}$ sodium nitrite $\left(\mathrm{NaNO}_{2}\right)$ as the sole $\mathrm{N}$ source to serve as a control for growth on $\mathrm{NO}_{2}{ }^{-}$and in Pro99 medium using $800 \mu \mathrm{M} \mathrm{NO}_{3}{ }^{-}$as the sole $\mathrm{N}$ source to serve as control for the absence of growth on $\mathrm{NO}_{3}{ }^{-}$. The co-cultures and pure cultures were sampled daily over 2 sequential transfers to monitor cell abundances with flow cytometry, $\mathrm{NO}_{2}{ }^{-}$concentrations using the Griess method, and to prepare qPCR filters for strain specific cell abundance measurements (Supplementary Materials and Methods).

Quantitative PCR assay. Given that the cell size and fluorescence properties of MIT0915, MIT0917, and MIT1214 overlap when examined using flow cytometry (all are LLI clade cells with similar size and chlorophyll content), we used qPCR to assess the cell abundance of each strain in co-culture. For MIT0915 and MIT0917, we used an assay that we had previously developed for detection of $\operatorname{narB}$ in these strains [10]. For the detection of MIT1214 we designed a qPCR assay to target the $w c k A$ gene (encoding a polysaccharide pyruvyl transferase family 
protein) in MIT1214 that is absent in both MIT0915 and MIT0917. Sample processing, standards, reaction conditions, and amplification efficiencies are detailed in the Supplementary Materials and Methods.

\section{RESULTS AND DISCUSSION}

Prochlorococcus strains produce $\mathrm{NO}_{2}^{-}$during growth on $\mathrm{NO}_{3}^{-} \cdot \mathrm{NO}_{2}^{-}$accumulation and release by phytoplankton growing on $\mathrm{NO}_{3}{ }^{-}$can arise from a bottleneck in the $\mathrm{NO}_{3}{ }^{-}$assimilation pathway. One possible cause of this bottleneck is limited availability of reducing power - the reduction of $\mathrm{NO}_{3}{ }^{-}$requires 2 electrons, while the reduction of $\mathrm{NO}_{2}^{-}$requires 6 electrons. Thus, we first asked whether Prochlorococcus, as well as the closely-related Synechococcus, exhibit incomplete assimilatory $\mathrm{NO}_{3}{ }^{-}$reduction with concomitant $\mathrm{NO}_{2}{ }^{-}$release [22]. To address this question, we leveraged a collection of strains in the MIT Cyanobacteria Culture Collection (Table S1). One includes the $\mathrm{NO}_{3}{ }^{-}$assimilating Prochlorococcus SB, a member of the high-light adapted HLII clade of Prochlorococcus, which are abundant in warm subtropical surface waters. Among the low-light adapted LLI clade of Prochlorococcus, we have identified 3 configurations of the $\mathrm{NO}_{3}{ }^{-}$and $\mathrm{NO}_{2}{ }^{-}$assimilation gene cassette [11], each represented in our study by the MIT1214, MIT0915, and MIT0917 strains (Table S1). MIT1214 has the capacity for $\mathrm{NO}_{2}{ }^{-}$ assimilation, but not $\mathrm{NO}_{3}{ }^{-}$assimilation - i.e., it has lost the upstream half of the $\mathrm{NO}_{3}{ }^{-}$ assimilation pathway, but has retained the downstream half for the assimilation of the more reduced $\mathrm{NO}_{2}{ }^{-}$. MIT0915 can assimilate $\mathrm{NO}_{3}{ }^{-}$and also possess a $\mathrm{NO}_{2}{ }^{-}$specific transporter (FocA) and a $\mathrm{NO}_{2}{ }^{-}$reductase (NirA) that are both closely related to those found in MIT1214. MIT0917 can also assimilate $\mathrm{NO}_{3}{ }^{-}$, but in contrast to MIT0915, this strain has a divergent version of NirA and has also lost the gene encoding the FocA $\mathrm{NO}_{2}{ }^{-}$transporter [11]. The Synechococcus strains examined included WH7803 and WH8102. While the environmental distribution of the former is not well resolved, the latter is adapted to warm oligotrophic waters and has a range that overlaps with the abundant HLII clade of Prochlorococcus [32]. WH7803 belongs to subcluster 5.1B and has both the FocA $\mathrm{NO}_{2}{ }^{-}$transporter and the dual specific $\mathrm{NO}_{3}{ }^{-} / \mathrm{NO}_{2}{ }^{-} \mathrm{NapA}$ transporter. WH8102 belongs to subcluster 5.1A and lacks the $\mathrm{FocA} \mathrm{NO}_{2}^{-}$transporter. 
We looked for evidence of extracellular accumulation of $\mathrm{NO}_{2}^{-}$during the growth of

Prochlorococcus and Synechococcus strains on $\mathrm{NO}_{3}{ }^{-}$with respect to growth on $\mathrm{NH}_{4}{ }^{+}$as the sole

$\mathrm{N}$ sources. Given that reducing power is ultimately derived from photochemistry in

cyanobacteria, we also tested if extracellular accumulation of $\mathrm{NO}_{2}{ }^{-}$might be enhanced during growth at lower light intensities. We found that Prochlorococcus MIT0917 cultures accumulated substantial concentrations of $\mathrm{NO}_{2}{ }^{-}$when provided $\mathrm{NO}_{3}{ }^{-}$as the sole $\mathrm{N}$ source (Fig. 1), compared

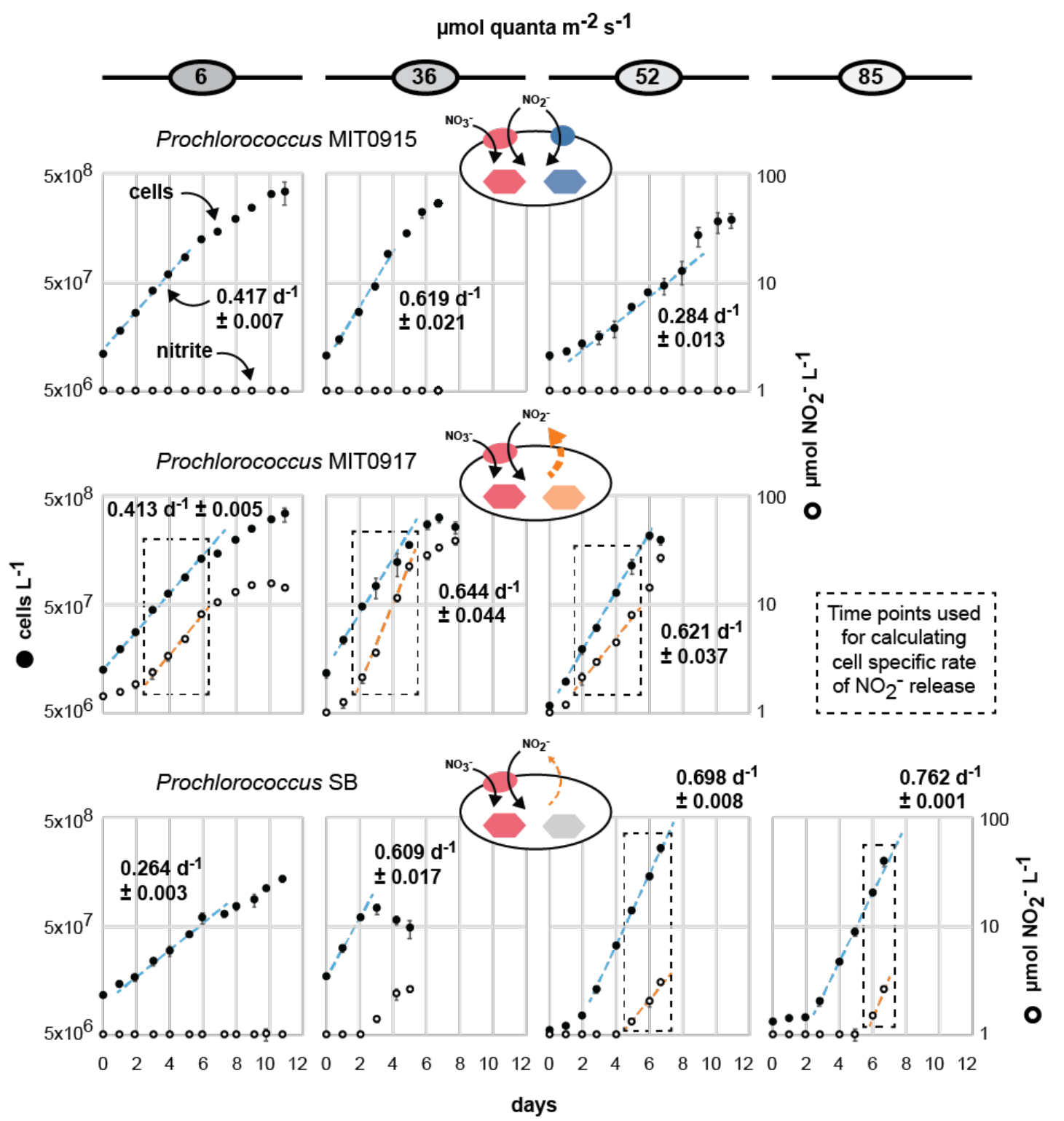

Fig. 1. $\mathrm{NO}_{2}{ }^{-}$accumulation in batch cultures of Prochlorococcus during growth on $\mathrm{NO}_{3}{ }^{-}$as the sole $\mathrm{N}$ source over a range of light intensities. Both Prochlorococcus MIT0917 (LLI clade) and Prochlorococcus SB (HLII clade) were observed to accumulate extracellular $\mathrm{NO}_{2}{ }^{-}$when provided $\mathrm{NO}_{3}{ }^{-}$as the sole $\mathrm{N}$ source. $\mathrm{NO}_{2}{ }^{-}$concentrations below the dynamic range of the assay $\left(<1 \mu \mathrm{M} \mathrm{NO}_{2}^{-}\right)$are plotted on the $\mathrm{x}$-axis. Cell-specific rates of $\mathrm{NO}_{2}^{-}$release $\left(\mathrm{nmol} \mathrm{NO} 2^{-}\right.$cell $\left.^{-1} \mathrm{~d}^{-1}\right)$ were calculated from the log-linear portion of the growth curve. 
to growth on $\mathrm{NH}_{4}{ }^{+}$(Fig. S1). In contrast, $\mathrm{NO}_{2}^{-}$concentrations remained below $1 \mu \mathrm{M}$ (the lower limit of the dynamic range for our assay) in cultures of the closely-related MIT0915 strain during growth on $\mathrm{NO}_{3}^{-}$(Fig. 1). The high-light adapted Prochlorococcus $\mathrm{SB}$ did accumulate $\mathrm{NO}_{2}{ }^{-}$in the culture medium during growth on $\mathrm{NO}_{3}{ }^{-}$, but at substantially lower concentrations compared to MIT0917 (Fig. 1). In comparison to the Prochlorococcus strains examined, neither of the Synechococcus strains produced levels of $\mathrm{NO}_{2}{ }^{-}$that exceeded $1 \mu \mathrm{M}$ during growth on $\mathrm{NO}_{3}{ }^{-}$or $\mathrm{NH}_{4}{ }^{+}$(Figs. 2 and S2). Overall, these data show that some strains of Prochlorococcus exhibit incomplete assimilatory $\mathrm{NO}_{3}{ }^{-}$reduction with concomitant release of $\mathrm{NO}_{2}{ }^{-}$.

We next examined the net cell-specific $\mathrm{NO}_{2}^{-}$production rates of MIT0917 and SB during growth on $\mathrm{NO}_{3}{ }^{-}$. The rates of $\mathrm{NO}_{2}^{-}$excretion by the low-light adapted Prochlorococcus MIT0917 was significantly greater than that for the high-light adapted Prochlorococcus SB (Fig. 3). At the same light intensity of $52 \mu \mathrm{mol}$ photons $\mathrm{m}^{-2} \mathrm{~s}^{-1}$, MIT0917 produced $\mathrm{NO}_{2}{ }^{-}$at a 5 -fold higher rate compared to SB (Fig. 3). The rate of $\mathrm{NO}_{2}^{-}$production by MIT0917 was highest at 36 and 52

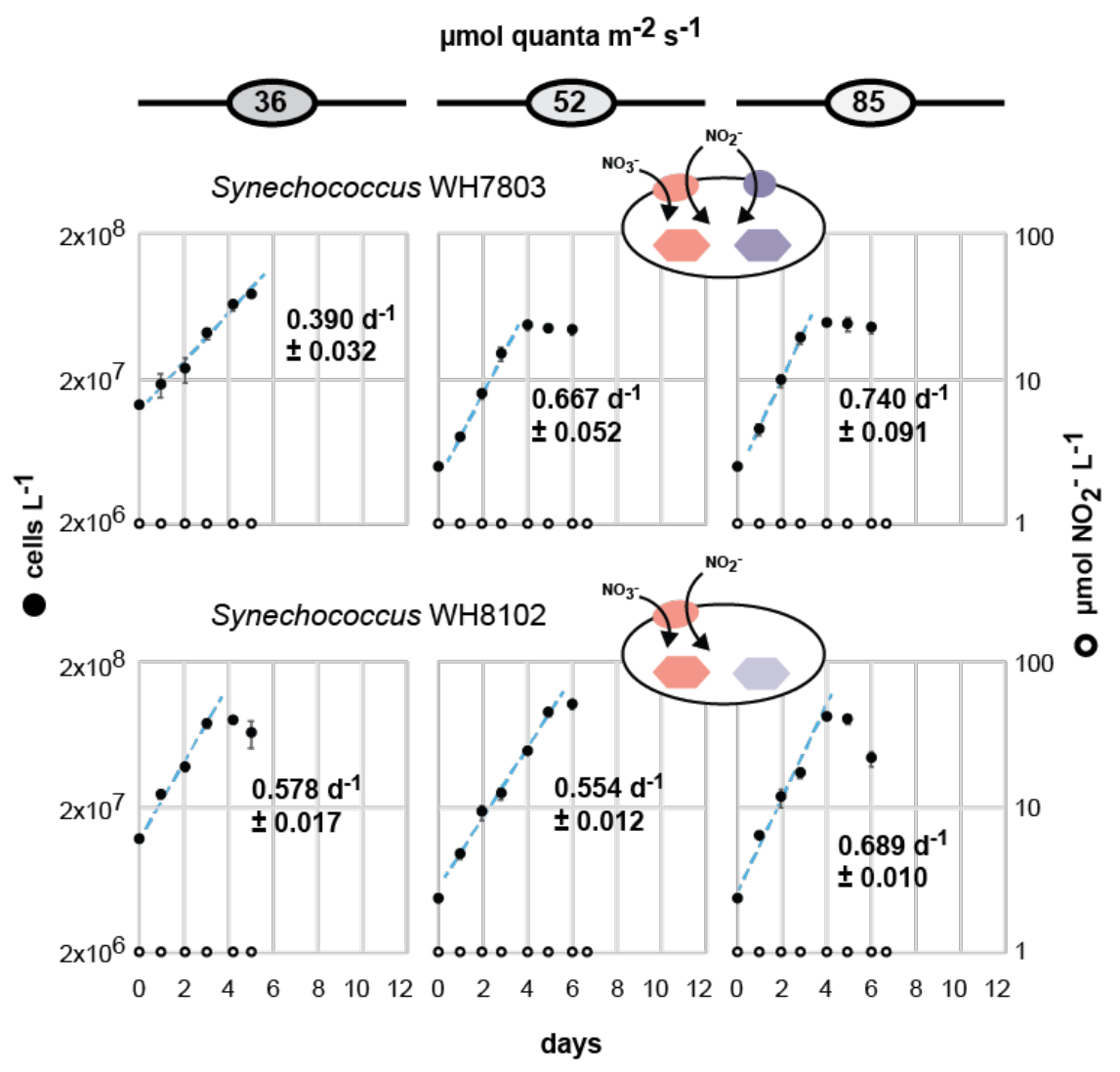

Fig. 2. $\mathrm{NO}_{2}{ }^{-}$accumulation in batch cultures of Synechococcus during growth on $\mathrm{NO}_{3}{ }^{-}$as the sole $\mathrm{N}$ source over a range of light intensities. Neither Synechococcus strain accumulated extracellular $\mathrm{NO}_{2}{ }^{-}$. $\mathrm{NO}_{2}{ }^{-}$concentrations below the dynamic range of the assay $\left(<1 \mu \mathrm{M} \mathrm{NO}_{2}^{-}\right)$are plotted on the $\mathrm{x}$-axis. 
$\mu$ mol photons $\mathrm{m}^{-2} \mathrm{~s}^{-1}$ in comparison to the lowest light intensity examined. These rates are necessarily inclusive of potential reuptake of $\mathrm{NO}_{2}{ }^{-}$by the dual specific $\mathrm{NO}_{3}{ }^{-} / \mathrm{NO}_{2}{ }^{-} \mathrm{NapA}$ transporter encoded by both of these strains. Nevertheless, reuptake of $\mathrm{NO}_{2}{ }^{-}$could be limited by the fact that the molar equivalents of $\mathrm{NO}_{3}{ }^{-}$would exceed that of $\mathrm{NO}_{2}{ }^{-}$by at least one order of magnitude throughout the entire growth curve.

We next wondered how consequential these rates of $\mathrm{NO}_{2}^{-}$release by MIT0917 were with respect to the $\mathrm{N}$ requirements of low-light adapted Prochlorococcus. To evaluate this question, we assumed a cellular $\mathrm{N}$ quota of 4.3 fg $\mathrm{N} \mathrm{cell}^{-1}$ for LLI Prochlorococcus [33] and minimal reuptake of $\mathrm{NO}_{2}^{-}$. Based on these assumptions, we find that approximately 20$30 \%$ of the $\mathrm{NO}_{3}{ }^{-}$transported into the cell by MIT0917 during exponential growth was

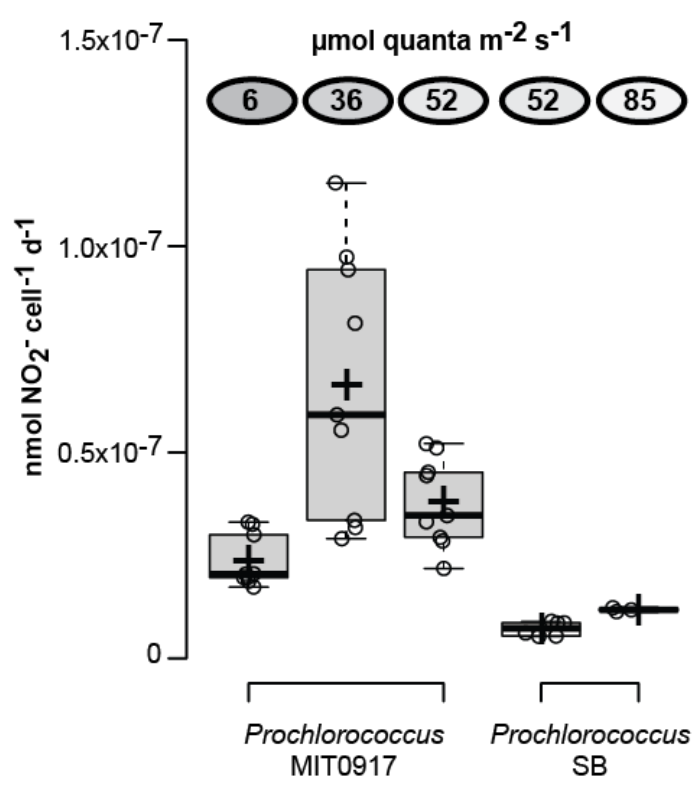

Fig. 3. Cell-specific $\mathrm{NO}_{2}{ }^{-}$production rates for two strains of Prochlorococcus, as a function of light intensity, when grown on $\mathrm{NO}_{3}{ }^{-}$as the sole $\mathrm{N}$ source. Mean (+/- standard deviation) of $\mathrm{NO}_{2}^{-}$production rates for MIT0917 were $2.4 \times 10^{-8}\left(+/-6.4 \times 10^{-9}\right)$, 6.6 $\times 10^{-8}\left(+/-3.2 \times 10^{-8}\right)$, and $3.8 \times 10^{-8}\left(+/-1.1 \times 10^{-8}\right)$ nmol $\mathrm{NO}_{2}^{-}$cell-1 $\mathrm{d}^{-1}$ at light intensities of 6,36 , and $52 \mu \mathrm{mol}$ photons $\mathrm{m}^{-2} \mathrm{~s}^{-1}$, respectively. SB produced nitrite at rates of $7.2 \times 10^{-9}\left(+/-1.7 \times 10^{-9}\right)$ and $1.2 \times$ $10^{-8}\left(+/-5.0 \times 10^{-10}\right) \mathrm{nmol} \mathrm{NO}_{2}^{-}$cell $^{-1} \mathrm{~d}^{-1}$ at light intensities of 52 and $85 \mu \mathrm{mol}$ photons $\mathrm{m}^{-2} \mathrm{~s}^{-1}$, respectively. Medians are denoted by solid black lines and means are denoted by crosses.

released as $\mathrm{NO}_{2}{ }^{-}$, with the balance assimilated into biomass (i.e., the proportion of $\mathrm{N}$ as extracellular $\mathrm{NO}_{2}^{-}$relative to the combined $\mathrm{N}$ in both biomass and extracellular $\mathrm{NO}_{2}^{-}$). Overall, these data demonstrate that some strains belonging to an abundant low-light adapted clade of Prochlorococcus can release high amounts of $\mathrm{NO}_{2}{ }^{-}$when provided $\mathrm{NO}_{3}{ }^{-}$as the sole $\mathrm{N}$ source.

\section{Contrasting features of $\mathrm{NO}_{3}^{-}$and $\mathrm{NO}_{2}^{-}$flow in Prochlorococcus and Synechococcus. Based}

on what is known about the gene content [11] and physiology (Figs. 1 and 2) of these strains, we can assign hypothetical pathways of inorganic N flow (Fig. 4). For LLI Prochlorococcus, these hypothetical pathways map onto the 3 distinct configurations of the $\mathrm{NO}_{3}{ }^{-}$and $\mathrm{NO}_{2}{ }^{-}$assimilation gene cassette that we have observed in their genomes [11]. Many LLI Prochlorococcus have the configuration represented by MIT1214 - that is, they can assimilate both $\mathrm{NH}_{4}{ }^{+}$and $\mathrm{NO}_{2}{ }^{-}$, but not $\mathrm{NO}_{3}{ }^{-}$. The remaining LLI Prochlorococcus - those represented by the $\mathrm{NO}_{3}{ }^{-}$assimilating strains, 
MIT0915 and MIT0917 - have contrasting features with regard to $\mathrm{NO}_{2}^{-}$production potential (Fig. 4). Under the N-replete conditions we examined, MIT0917 accumulated high extracellular quantities of $\mathrm{NO}_{2}^{-}$relative to the proportion of $\mathrm{N}$ that was ultimately assimilated into biomass. The closely related MIT0915 strain, however, released negligible quantities of $\mathrm{NO}_{2}^{-}$under the same conditions.

Prochlorococcus $\mathrm{SB}$ produced much less $\mathrm{NO}_{2}^{-}$during growth on $\mathrm{NO}_{3}{ }^{-}$than Prochlorococcus MIT0917 - and only at the highest light intensities examined - but, similar to MIT0917, SB also lacks the FocA $\mathrm{NO}_{2}{ }^{-}$transporter (Fig. 4). Prochlorococcus SB belongs to the high-light adapted HLII clade, which is the most abundant clade of Prochlorococcus globally and can represent $>90 \%$ of depth integrated Prochlorococcus in warm tropical and subtropical waters [15]. Although the culturing conditions we employed are quite different than those that cells experience in the wild, HLII clade cells with the potential for $\mathrm{NO}_{2}{ }^{-}$release - even if less than that

Prochlorococcus
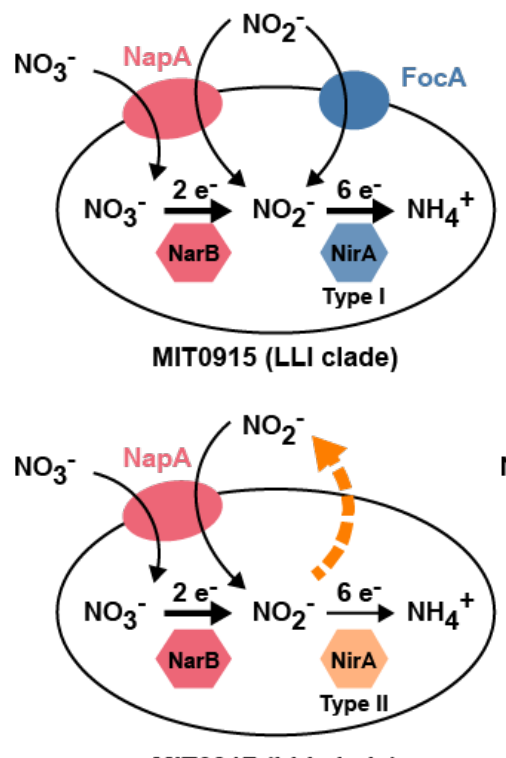

MIT0917 (LLI clade)
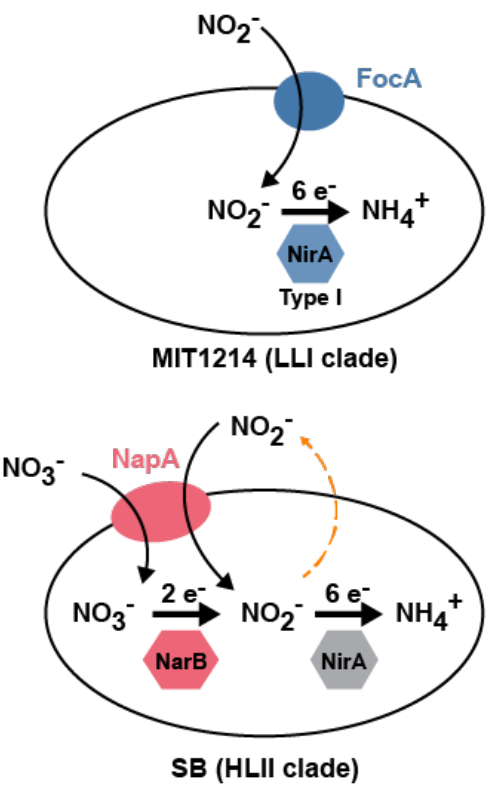

Synechococcus

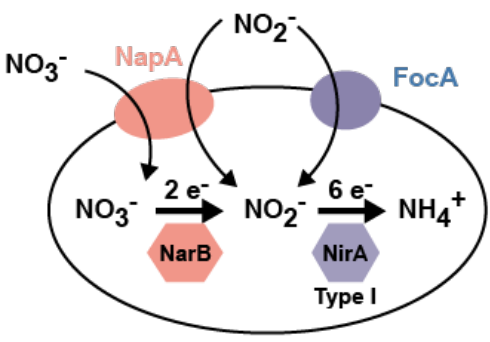

WH7803 (Subcluster 5.1B ; Clade V)

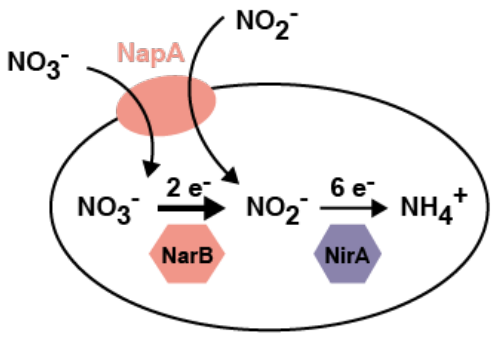

WH8102 (Subcluster 5.1A; Clade IIII)

Fig. 4. Hypothetical cellular inorganic N inputs and outputs for Prochlorococcus and Synechococcus strains are based on physiology data (Figs. 1 and 2) and functional annotation of pathway proteins [11]. SB lacks a dedicated $\mathrm{NO}_{2}{ }^{-}$transporter (FocA), but can take up $\mathrm{NO}_{2}{ }^{-}$using the dual-specific $\mathrm{NO}_{3}-\mathrm{NO}_{2}{ }^{-} \mathrm{NapA}$ transporter. MIT0917 has a Type II NirA and lacks the FocA $\mathrm{NO}_{2}{ }^{-}$transporter. Both SB and MIT0917 excrete $\mathrm{NO}_{2}^{-}$(dashed orange arrow). MIT0915 has a Type I NirA and has also retained the FocA $\mathrm{NO}_{2}{ }^{-}$transporter - MIT0915 did not excrete $\mathrm{NO}_{2}{ }^{-}$during growth on $\mathrm{NO}_{3}{ }^{-}$(Fig. 1). MIT1214 has lost the upstream half of the $\mathrm{NO}_{3}{ }^{-}$assimilation pathway, but has retained FocA and the Type I NirA for the transport and assimilation of $\mathrm{NO}_{2}{ }^{-}$. In comparison to the Prochlorococcus strains examined, neither Synechococcus strain releases $\mathrm{NO}_{2}{ }^{-}$during growth on $\mathrm{NO}_{3}^{-}$. WH7803 possesses the FocA $\mathrm{NO}_{2}{ }^{-}$transporter, while WH8102 does not. 
of some LLI clade cells - could have an important impact on $\mathrm{NO}_{2}{ }^{-}$cycling in the global ocean due to their sheer abundance. Synechococcus, while broadly distributed and responsible for a greater fraction of net primary production compared to Prochlorococcus, does not appear to release $\mathrm{NO}_{2}^{-}$in batch culture (Figs. 2 and 4). An important caveat is that the strains we examined represent only a fraction of the diversity of Synechococcus.

\section{Wild populations of LLI clade Prochlorococcus are composed of coexisting functional types} delineated by their use of $\mathrm{NO}_{3}{ }^{-}$and $\mathrm{NO}_{2}^{-}$. In both the subtropical North Pacific and North Atlantic oceans, LLI Prochlorococcus (either with or without the capacity for $\mathrm{NO}_{3}{ }^{-}$assimilation) often reach maximum abundance within the subsurface chlorophyll maximum layer [15] and in the vicinity of the primary $\mathrm{NO}_{2}^{-}$maximum layer [10]. Our data now indicate that there is a significant degree of phenotypic diversity with respect to the use of $\mathrm{NO}_{2}{ }^{-}$and $\mathrm{NO}_{3}{ }^{-}$and that this functional diversity maps onto the genomic diversity of the LLI clade of Prochlorococcus. Given these observations, how are LLI Prochlorococcus populations structured with respect to the 3 distinct functional types that we have identified (Fig. 4)? To address this question, we turned to metagenomic data [34] from the subsurface chlorophyll maximum layer at time-series stations in the North Pacific Subtropical Gyre (Hawai'i Ocean Time-series; HOT) and the North Atlantic Subtropical Gyre (Bermuda Atlantic Time-series Study; BATS).

In both the North Pacific and the North Atlantic subtropical gyres, we observed that MIT1214like cells (those that assimilate $\mathrm{NO}_{2}^{-}$but not $\mathrm{NO}_{3}^{-}$) dominated the LLI Prochlorococcus populations throughout the year and generally exceeded $60 \%$ of total LLI genomes (Fig. 5). In the North Pacific ecosystem, overall frequencies of each functional type were quite stable on seasonal time scales, with each of the $\mathrm{NO}_{3}{ }^{-}$assimilating functional types making up roughly $15 \%$ of the population (Fig. 5). In contrast, the seasonal dynamics in the North Atlantic ecosystem were readily apparent. Frequencies of the $\mathrm{NO}_{3}{ }^{-}$assimilating functional types waned in the winter and spring and then increased through the summer and autumn (Fig. 5). These observations are consistent with previous work that demonstrated higher abundances of HLII Prochlorococcus with the potential for $\mathrm{NO}_{3}{ }^{-}$assimilation during the summer and autumn in the North Atlantic [10], when overall surface $\mathrm{N}$ concentrations were low. The MIT0915-like functional type (the one that did not exhibit incomplete assimilatory $\mathrm{NO}_{3}{ }^{-}$reduction in our culture experiments) generally dominated the $\mathrm{NO}_{3}{ }^{-}$assimilating functional types in the North Atlantic ecosystem's LLI Prochlorococcus populations (Fig. 5). In contrast, higher frequencies of the MIT0917-like 


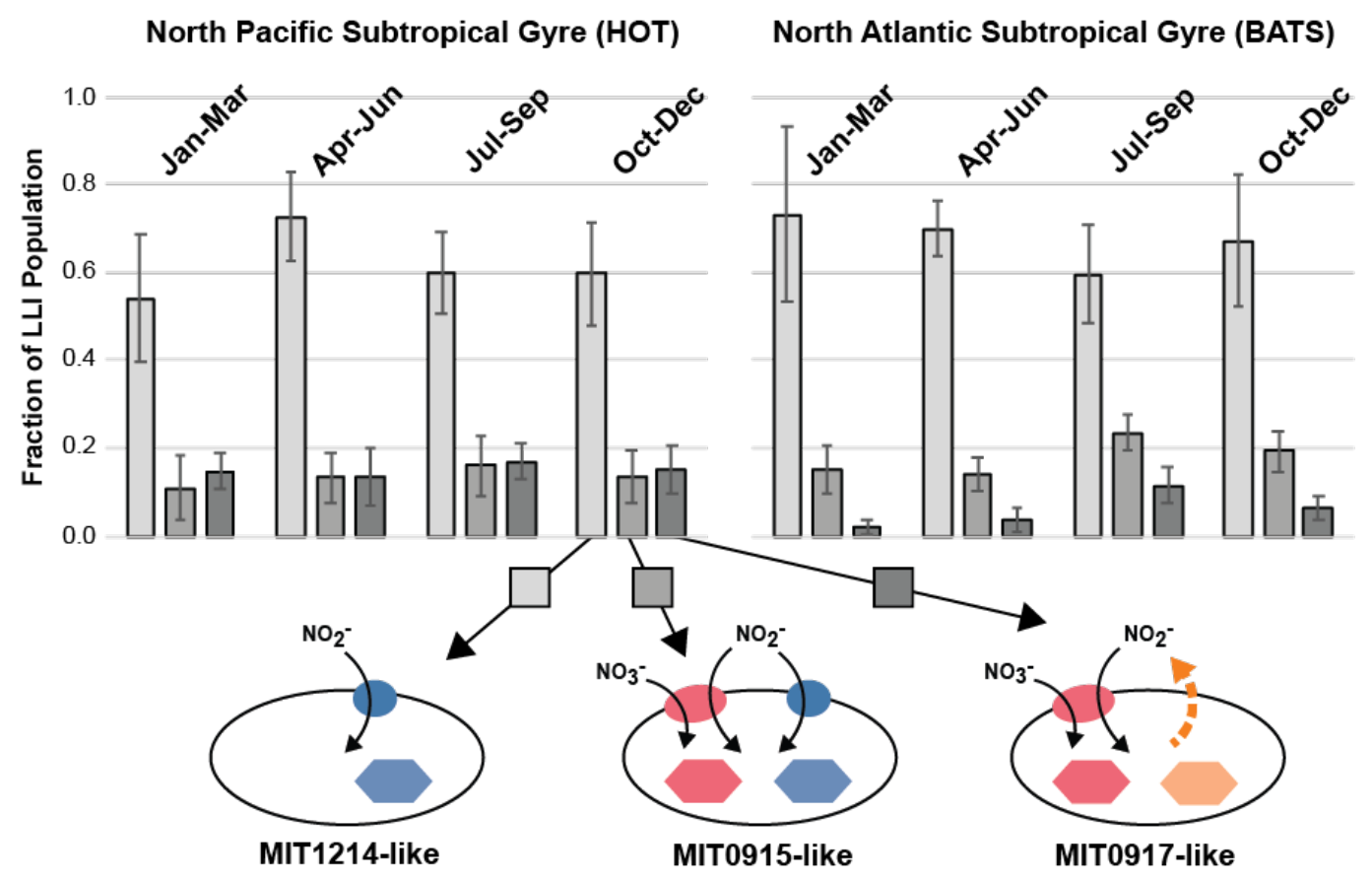

Fig. 5. Distribution of functional types in the LLI clade Prochlorococcus (based on N flow pathways in Fig. 4) in the North Pacific and North Atlantic subtropical gyres. $\mathrm{NO}_{3}{ }^{-}$assimilating genotypes are abundant in the North Pacific throughout the year. Putative $\mathrm{NO}_{2}^{-}$producers (MIT0917-like) reach maximum abundance in the North Atlantic during summer stratification of the water column. $\mathrm{NO}_{2}{ }^{-}$consumers (MIT1214-like) typically account for $>50 \%$ of the LLI populations in both ecosystems.

functional type (the one that releases $\mathrm{NO}_{2}^{-}$) in the North Pacific compared to the North Atlantic suggests its configuration of the $\mathrm{NO}_{3}{ }^{-}$assimilation gene cassette may be better adapted to the stable, well-stratified, and generally N-limited waters of the North Pacific Subtropical Gyre.

Prochlorococcus exchange $\mathbf{N}$ in experimental populations. Given that LLI Prochlorococcus with different $\mathrm{N}$ assimilation features (Fig. 4) coexist in the marine environment (Fig. 5), we next assessed whether strains with different $\mathrm{N}$ assimilation genotypes could form metabolic dependencies in the laboratory. To achieve this, we co-cultured Prochlorococcus MIT1214 (which can use $\mathrm{NO}_{2}^{-}$but not $\mathrm{NO}_{3}^{-}$) with either Prochlorococcus MIT0915 or Prochlorococcus MIT0917 (each of which can use both $\mathrm{NO}_{3}{ }^{-}$and $\mathrm{NO}_{2}{ }^{-}$) in medium containing $\mathrm{NO}_{3}{ }^{-}$as the sole $\mathrm{N}$ source.

Relative to pure cultures of MIT0917 (Fig. 6B, F), co-cultures of MIT1214 and MIT0917 did not accumulate $\mathrm{NO}_{2}{ }^{-}$in the culture medium during balanced exponential growth (Fig. 7A, B), because any $\mathrm{NO}_{2}{ }^{-}$released by MIT0917 was used to fulfill the $\mathrm{N}$ requirements of MIT1214. Some $\mathrm{NO}_{2}{ }^{-}$accumulation was observed as the MIT1214-MIT0917 co-culture approached 


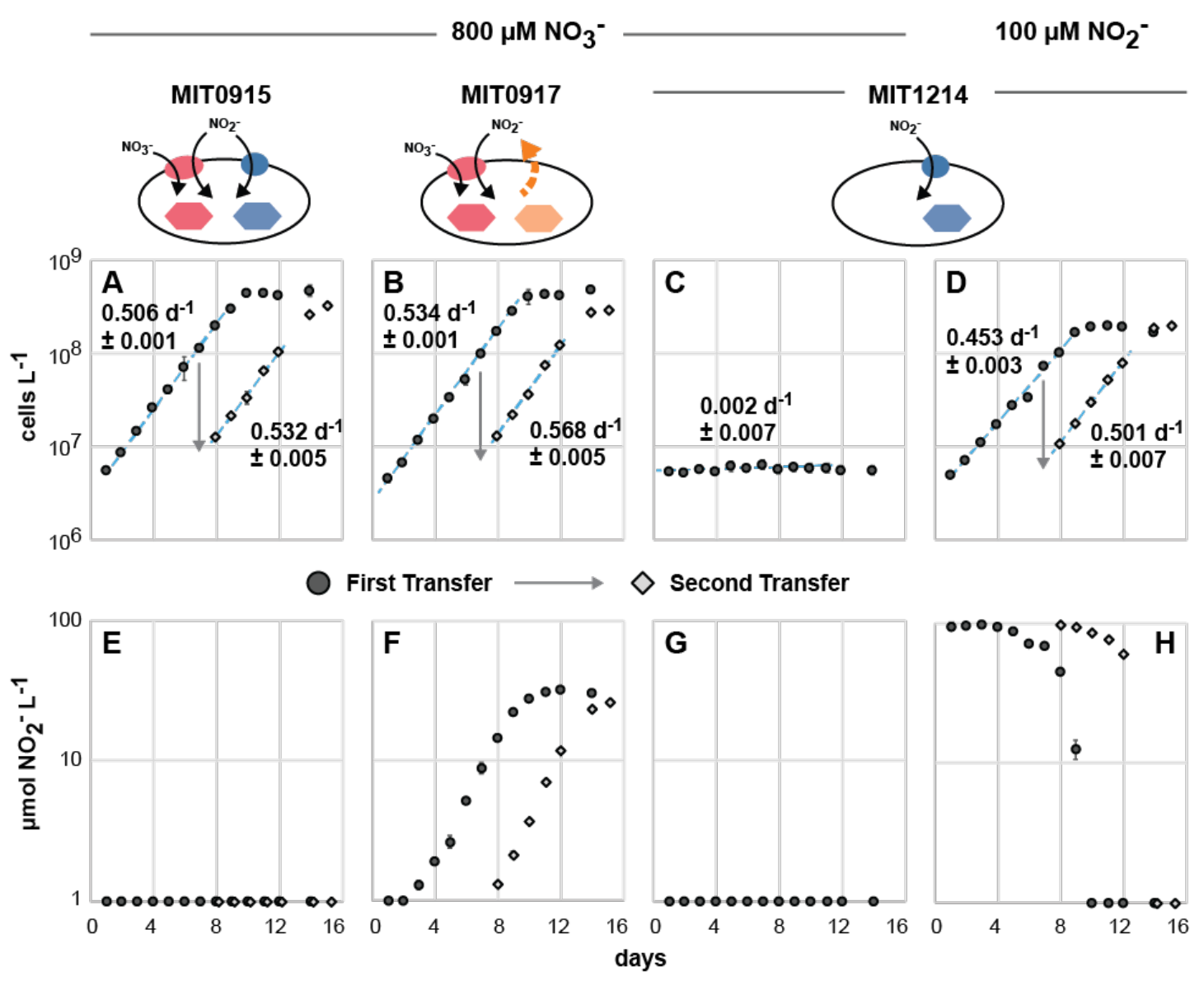

Fig. 6. Pure cultures of MIT0915, MIT0917, and MIT1214 followed over 2 transfers (black circles followed by gray diamonds) as contemporaneous controls for co-culture experiments. As pure cultures, MIT0915 and MIT0917 grow using $\mathrm{NO}_{3}{ }^{-}$(A, B), but only MIT0917 does so with concomitant release of $\mathrm{NO}_{2}^{-}$(E, F). MIT1214 cannot use $\mathrm{NO}_{3}{ }^{-}$as a $\mathrm{N}$ source $(\mathrm{C})$, but has retained the genes necessary for growth on $\mathrm{NO}_{2}^{-}(\mathrm{D}, \mathrm{H})$.

stationary phase (Fig. 7A, B), suggesting an imbalance between production and consumption of $\mathrm{NO}_{2}{ }^{-}$outside of balanced exponential growth. The growth rates of each of the two strains in coculture (Fig. 7C, D) were similar to their growth rates in pure culture (Fig. 6B, D), suggesting that MIT0917 could supply nearly all of the N needs of MIT1214. Further, we expect that the growth of MIT1214 under these conditions resembles growth in continuous culture systems i.e., in co-culture, MIT1214 was likely poised at some degree of N limitation with growth controlled by the rate of $\mathrm{NO}_{2}{ }^{-}$release by the partner strain. In these co-cultures, the frequency of the MIT1214 strain settled at roughly $30 \%$ of total cell numbers as determined by quantitative PCR (Fig. 7E) - providing additional support for our estimate that MIT0917 partially reduces and excretes up to $30 \%$ of the $\mathrm{NO}_{3}{ }^{-}$transported into the cell as extracellular $\mathrm{NO}_{2}{ }^{-}$. 
When MIT1214 was paired with MIT0915, a strain that does not produce $\mathrm{NO}_{2}{ }^{-}$when growing on $\mathrm{NO}_{3}{ }^{-}$in pure culture (Fig. 6A, E), we expected the growth of MIT1214 to stop after any carryover $\mathrm{NO}_{2}^{-}$from the inoculum was exhausted. On the contrary, MIT1214 continued to grow (Fig. 8D), but at significantly lower growth rates compared to either growth in the presence of MIT0917 using $\mathrm{NO}_{3}{ }^{-}$as the $\mathrm{N}$ source (Fig. 7D) or to the growth of MIT1214 in pure culture using $\mathrm{NO}_{2}^{-}$(Fig. 6D). As expected, $\mathrm{NO}_{2}^{-}$did not accumulate during the growth of the MIT1214MIT0915 co-culture (Fig. 8A, B). The frequency of the MIT1214 strain was driven to $<5 \%$ of total cell numbers over the course of 2 sequential transfers (Fig. 8E), likely as a consequence of
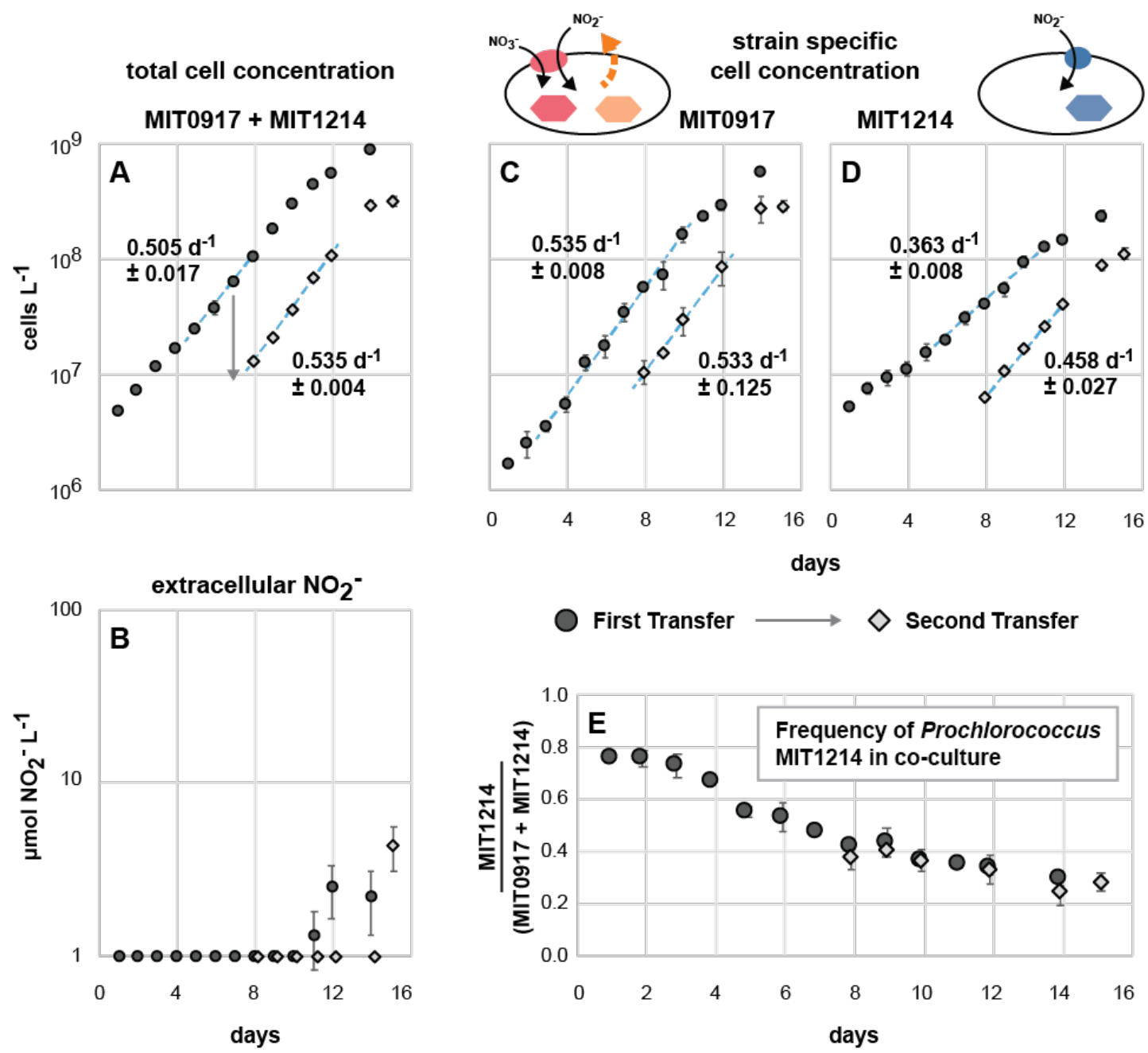

First Transfer $\longrightarrow \diamond$ Second Transfer

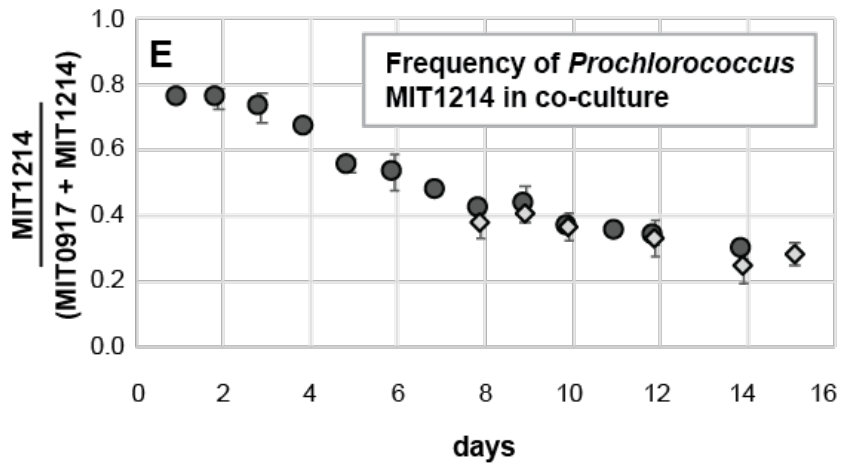

Fig. 7. Co-culture of Prochlorococcus MIT0917 ( $\mathrm{NO}_{2}^{-}$producer) and Prochlorococcus $\mathrm{MIT} 1214\left(\mathrm{NO}_{2}{ }^{-}\right.$ consumer). Total cell counts and specific growth rates were determined by flow cytometry (A). $\mathrm{NO}_{2}^{-}$does not accumulate in the co-culture during balanced exponential growth (B), instead being drawn down by MIT1214. The growth rates of the individual strains in the co-culture, assessed by quantitative PCR (C, D), were similar to those growing as pure cultures (Fig. 6). The frequency of MIT1214 in the co-culture converged at approximately $30 \%$ of total cell numbers after 2 transfers $(\mathrm{E})$. 

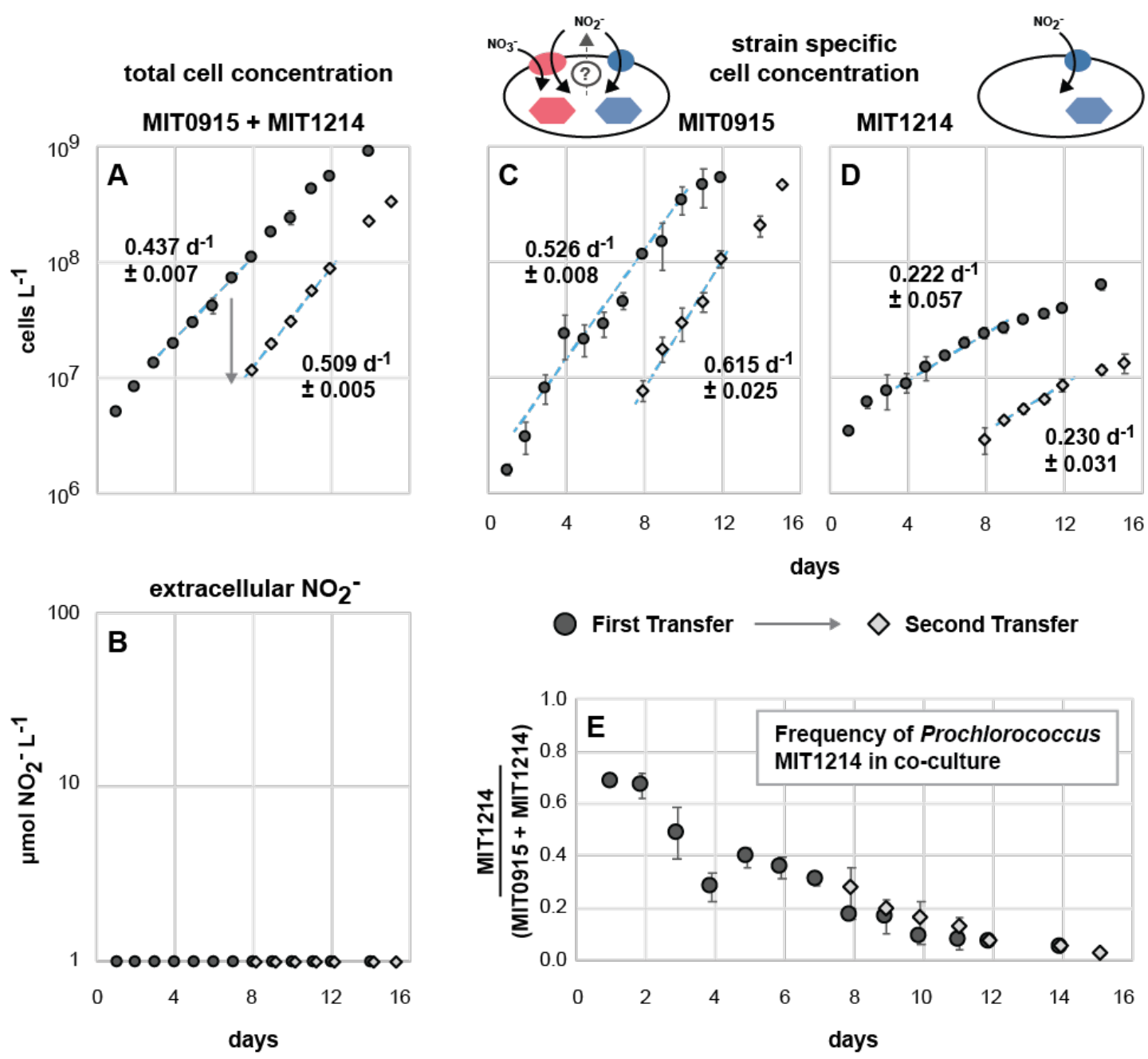

Fig. 8. Co-culture of Prochlorococcus MIT0915 and Prochlorococcus MIT1214. Total cell counts and specific growth rates were determined by flow cytometry (A). $\mathrm{NO}_{2}{ }^{-}$does not accumulate in the co-culture (B) as observed with pure cultures of MIT0915 (Fig. 6). As determined by quantitative PCR, MIT0915 maintained steady growth (C) while the growth rate of MIT1214 (D) declined by more than 50\% compared to growth as a pure culture using $\mathrm{NO}_{2}{ }^{-}$as the $\mathrm{N}$ source (Fig. 6). Although MIT1214 was driven to less than $5 \%$ of total cell numbers after 2 transfers (E), continued growth of the strain at a depressed growth rate suggests some level of cryptic $\mathrm{NO}_{2}^{-}$release by the MIT0915 strain (denoted in the cartoon schematic of N flow in MIT0915).

the MIT1214 strain's depressed growth rate in the presence of the MIT0915 strain. The continued slow growth of MIT1214 suggests the possibility that MIT0915 does produce low quantities of $\mathrm{NO}_{2}{ }^{-}$when growing on $\mathrm{NO}_{3}{ }^{-}$. Recall that MIT0915 also possesses a Foc $\mathrm{A} \mathrm{NO}_{2}{ }^{-}$ specific transporter (Fig. 4) - in contrast to MIT0917 - which may facilitate some reuptake of $\mathrm{NO}_{2}{ }^{-}$and thus maintain undetectable $\mathrm{NO}_{2}{ }^{-}$concentrations in pure culture (Fig. 6A, E). Supply of $\mathrm{NO}_{2}{ }^{-}$at rates that keep the concentration of $\mathrm{NO}_{2}{ }^{-}$at or below the half-saturation constant (Ks) for MIT1214's growth on $\mathrm{NO}_{2}^{-}$would be consistent with its significantly lower growth rate when co-cultured with MIT0915. 


\section{Causes and consequences of incomplete assimilatory $\mathrm{NO}_{3}^{-}$reduction by Prochlorococcus.}

Our work has uncovered new potential links between Prochlorococcus and the N cycle by demonstrating that some Prochlorococcus divert a sizable fraction of transported $\mathrm{NO}_{3}{ }^{-}$to extracellular pools of $\mathrm{NO}_{2}^{-}$. An intriguing feature of this phenomenon is the degree of phenotypic variability between strains. For Prochlorococcus cultures, the ability of some to accumulate $\mathrm{NO}_{2}^{-}$ (Figs. 1, 3, and 6F) maps onto each strain's particular version of the $\mathrm{NO}_{3}{ }^{-}$assimilation gene cluster [11]. Given the global abundance of Prochlorococcus in the world's oceans, the fraction of Prochlorococcus that release $\mathrm{NO}_{2}{ }^{-}$when reducing $\mathrm{NO}_{3}{ }^{-}$could have important consequences for our understanding of primary production and $\mathrm{N}$ cycle processes that occur in the tropical and subtropical ocean.

While many eukaryotic phytoplankton exhibit incomplete assimilatory $\mathrm{NO}_{3}{ }^{-}$reduction, this process is not well constrained for the picocyanobacteria that dominate the expansive subtropical gyres of the open ocean. Why would an organism such as Prochlorococcus, which is welladapted to life in oligotrophic habitats, release $\mathrm{N}$ back into its environment when this nutrient is often in limited supply? Our observations could be related to laboratory culture conditions where the concentrations of inorganic nutrients are much higher than would be observed in the field. Yet, only one functional type of LLI Prochlorococcus (represented by the MIT0917 strain) exhibited incomplete assimilatory $\mathrm{NO}_{3}{ }^{-}$reduction. It is possible that the divergent version of the NirA $\mathrm{NO}_{2}{ }^{-}$reductase possessed by MIT0917 - and similar Prochlorococcus in the field - has distinct biochemical features. One hypothesis is that this divergent NirA has a higher substrate affinity, perhaps providing these cells with an advantage under chronically $\mathrm{N}$ limited conditions. Under replete conditions in batch culture, these cells might experience a kinetic bottleneck at the $\mathrm{NO}_{2}{ }^{-}$reduction step of the $\mathrm{NO}_{3}{ }^{-}$assimilation pathway that results in cellular accumulation of $\mathrm{NO}_{2}^{-}$because $\mathrm{NO}_{3}{ }^{-}$reduction outpaces the $\mathrm{k}_{\text {cat }}$ of this divergent NirA. This $\mathrm{NO}_{2}^{-}$could then diffuse out of the cell as nitrous acid $\left(\mathrm{HNO}_{2}\right)$ which would make up a small fraction of the intracellular $\mathrm{NO}_{2}^{-}$pool at cellular $\mathrm{pH}$ [35]. Analogous field conditions would be intermittent upwellings of $\mathrm{NO}_{3}{ }^{-}$that temporarily increase local substrate supply [36].

Prochlorococcus MIT0917 also lacks the FocA NO${ }^{-}$specific transporter that is found in other LLI Prochlorococcus (Fig. 4), including the MIT0915 strain that does not exhibit extracellular accumulation of $\mathrm{NO}_{2}^{-}$in batch culture. An alternative, but not mutually exclusive, hypothesis for $\mathrm{NO}_{2}{ }^{-}$release by MIT0917 is that this strain lacks the capacity for cyclic retention of $\mathrm{NO}_{2}{ }^{-}$that 
may diffuse out of the cell as $\mathrm{HNO}_{2}$. It is common for bacteria to employ so-called "futile cycles" to mitigate the loss of nutrients and metabolites across the cell membrane [37, 38]. While this process expends energy, it can serve to regulate substrate retention and maintain sufficiently high concentrations of a substrate within the cell. MIT0917 may not require re-uptake of $\mathrm{NO}_{2}{ }^{-}$if its NirA is optimized for low internal substrate concentrations - in such a scenario, the foc $A$ gene could have been lost due to a general bias towards gene deletion in the absence of a sufficient selective advantage. The MIT0915 strain, on the other hand, might require a mechanism for cyclic retention of $\mathrm{NO}_{2}^{-}$if its NirA has a lower substrate affinity. Notably, we did observe slow growth of MIT1214 when in co-culture with MIT0915 (Fig. 8D), suggesting that MIT0915 might release some quantities of $\mathrm{NO}_{2}^{-}$to the extracellular milieu - this would put it in competition with MIT1214 for access to $\mathrm{NO}_{2}^{-}$in order to maintain sufficiently high cellular $\mathrm{NO}_{2}{ }^{-}$ concentrations.

Our laboratory-based observations suggest that Prochlorococcus may interact with the primary $\mathrm{NO}_{2}^{-}$maximum layer in complicated ways. Although this feature is ubiquitous in stratified oceanic water columns, it is still unclear what mechanisms are responsible for its emergence. In addition to eroding the primary $\mathrm{NO}_{2}^{-}$maximum layer through $\mathrm{NO}_{2}^{-}$uptake and assimilation, Prochlorococcus also appears to have the potential to amplify the magnitude of the primary $\mathrm{NO}_{2}{ }^{-}$ maximum layer. At present, it is unclear if Prochlorococcus exhibit $\mathrm{NO}_{2}^{-}$release in the wild and, if so, what abiotic and biotic factors might influence $\mathrm{NO}_{2}^{-}$cycling in these populations. Extrapolating from $\mathrm{NO}_{2}{ }^{-}$production rates for both Prochlorococcus and ammonia-oxidizing archaea as well as the abundance of marker genes for these microbes in the field, we postulate that $\mathrm{NO}_{2}^{-}$production by Prochlorococcus could be responsible for some degree of $\mathrm{NO}_{2}{ }^{-}$ produced in the euphotic zone. Prochlorococcus MIT0917 releases $\mathrm{NO}_{2}{ }^{-}$at rates from $2 \times 10^{-8}$ nmol $\mathrm{NO}_{2}^{-}$cell $^{-1} \mathrm{~d}^{-1}$ up to $7 \times 10^{-8} \mathrm{nmol} \mathrm{NO}_{2}^{-}$cell-1 $^{-1} \mathrm{~d}^{-1}$ (Fig. 3). In comparison, the dominant ammonia-oxidizing microorganism in subtropical open ocean ecosystems, Candidatus Nitrosopelagicus brevis [39], produces $\mathrm{NO}_{2}^{-}$at a rate of about $2 \times 10^{-6} \mathrm{nmol} \mathrm{NO}_{2}^{-}$cell-1 $^{-1} \mathrm{~d}^{-1}$ in batch culture [40]. Ammonia-oxidizing archaea are thus expected to produce $\mathrm{NO}_{2}{ }^{-}$at 30-100 fold higher rates than Prochlorococcus, but the latter is often more abundant. For instance, ammoniaoxidizing archaea in the epipelagic zone have been typically observed at abundances of 1,0006,000 amoA gene copies $\mathrm{mL}^{-1}[21,41,42]$. Low-light adapted Prochlorococcus with the capacity of $\mathrm{NO}_{3}{ }^{-}$assimilation, however, can reach abundances of $1,000-40,000$ cells $\mathrm{mL}^{-1}$ in the vicinity 
of the subsurface chlorophyll maximum layer [10]. Therefore, depending on both rates and cell abundances, Prochlorococcus could be responsible from anywhere between $<1 \%$ to approximately $50 \%$ of $\mathrm{NO}_{2}^{-}$production in the mid-euphotic zone as a fraction of Prochlorococcus and nitrifier derived $\mathrm{NO}_{2}^{-}$. Under some conditions, Prochlorococcus might rival the $\mathrm{NO}_{2}{ }^{-}$production by ammonia-oxidizing archaea.

As we have demonstrated, different functional types of Prochlorococcus can coexist under conditions where $\mathrm{NO}_{2}{ }^{-}$cross-feeding is promoted and $\mathrm{NO}_{2}^{-}$accumulation is minimized (Fig. 7). Consequently, $\mathrm{NO}_{2}^{-}$production and consumption in Prochlorococcus populations might be a cryptic process whereby there is no net accumulation of $\mathrm{NO}_{2}^{-}$at steady-state. In the wild, Prochlorococcus populations could dynamically assemble in response to the availability of $\mathrm{N}$ sources of varying redox state as well as in response to community-wide competition for these $\mathrm{N}$ sources. Net $\mathrm{NO}_{2}{ }^{-}$accumulation might only occur within these populations during periods of perturbation (e.g., changes in light intensity or nutrient supply). Additional study is warranted to examine the conditions under which Prochlorococcus populations are either net producers or net consumers of $\mathrm{NO}_{2}{ }^{-}$and evaluate how microbial populations and communities modulate the availability of various $\mathrm{N}$ sources that ultimately impact production and remineralization processes in N-limited systems. At the population level, the dynamic assembly of distinct functional types of Prochlorococcus could emerge through interactions that are mediated, in part, by cross-feeding of $\mathrm{NO}_{2}^{-}$. We posit that trait variability and the selection of complementary functions might facilitate robustness or resiliency in microbial populations. Prochlorococcus, as a key primary producer in the tropical and subtropical ocean, offers an extremely valuable lens through which to constrain the rules under which emergent features arise.

\section{ACKNOWLEDGEMENTS}

This work was supported by grants from the National Science Foundation (OCE- 2048470 to P.M.B.) and the Simons Foundation (Life Sciences Project Award ID 337262, S.W.C; SCOPE Award ID 329108, S.W.C.). The authors thank Rogier Braakman (MIT) for insightful discussions. This paper is a contribution from the Simons Collaboration on Ocean Processes and Ecology (SCOPE). 


\section{COMPETING INTERESTS}

The authors declare no competing financial interests.

\section{REFERENCES}

1. Flombaum P, Gallegos JL, Gordillo RA, Rincón J, Zabala LL, Jiao N, et al. Present and future global distributions of the marine Cyanobacteria Prochlorococcus and Synechococcus. Proc Natl Acad Sci USA. 2013;110:9824-9829.

2. Agusti S, Lubián LM, Moreno-Ostos E, Estrada M, Duarte CM. Projected changes in photosynthetic picoplankton in a warmer subtropical ocean. Front Mar Sci. 2019;5:506.

3. Tyrrell T. The relative influences of nitrogen and phosphorus on oceanic primary production. Nature. 1999;400:525-531.

4. Ohashi Y, Shi W, Takatani N, Aichi M, Maeda S-I, Watanabe S, et al. Regulation of nitrate assimilation in cyanobacteria. J Exp Bot. 2011;62:1411-1424.

5. Coleman ML, Chisholm SW. Code and context: Prochlorococcus as a model for crossscale biology. Trends Microbiol. 2007;15:398-407.

6. Kettler GC, Martiny AC, Huang K, Zucker J, Coleman ML, Rodrigue S, et al. Patterns and implications of gene gain and loss in the evolution of Prochlorococcus. PLoS Genet. 2007;3:e231.

7. Biller SJ, Berube PM, Lindell D, Chisholm SW. Prochlorococcus: the structure and function of collective diversity. Nat Rev Microbiol. 2015;13:13-27.

8. Martiny AC, Kathuria S, Berube PM. Widespread metabolic potential for nitrite and nitrate assimilation among Prochlorococcus ecotypes. Proc Natl Acad Sci USA. 2009;106:1078710792.

9. Berube PM, Biller SJ, Kent AG, Berta-Thompson JW, Roggensack SE, Roache-Johnson KH, et al. Physiology and evolution of nitrate acquisition in Prochlorococcus. ISME J. 2015;9:1195-1207. 
10. Berube PM, Coe A, Roggensack SE, Chisholm SW. Temporal dynamics of Prochlorococcus cells with the potential for nitrate assimilation in the subtropical Atlantic and Pacific oceans. Limnol Oceanogr. 2016;61:482-495.

11. Berube PM, Rasmussen A, Braakman R, Stepanauskas R, Chisholm SW. Emergence of trait variability through the lens of nitrogen assimilation in Prochlorococcus. eLife. 2019;8:e41043.

12. Casey JR, Lomas MW, Mandecki J, Walker DE. Prochlorococcus contributes to new production in the Sargasso Sea deep chlorophyll maximum. Geophys Res Lett. 2007;34:L10604.

13. Moore LR, Post AF, Rocap G, Chisholm SW. Utilization of different nitrogen sources by the marine cyanobacteria Prochlorococcus and Synechococcus. Limnol Oceanogr. 2002;47:989-996.

14. Johnson ZI, Zinser ER, Coe A, McNulty NP, Woodward EMS, Chisholm SW. Niche partitioning among Prochlorococcus ecotypes along ocean-scale environmental gradients. Science. 2006;311:1737-1740.

15. Malmstrom RR, Coe A, Kettler GC, Martiny AC, Frias-Lopez J, Zinser ER, et al. Temporal dynamics of Prochlorococcus ecotypes in the Atlantic and Pacific oceans. ISME J. 2010;4:1252-1264.

16. Zinser ER, Johnson ZI, Coe A, Karaca E, Veneziano D, Chisholm SW. Influence of light and temperature on Prochlorococcus ecotype distributions in the Atlantic Ocean. Limnol Oceanogr. 2007;52:2205-2220.

17. West NJ, Scanlan DJ. Niche-partitioning of Prochlorococcus populations in a stratified water column in the eastern North Atlantic Ocean. Appl Environ Microbiol. 1999;65:25852591.

18. Letelier RM, Karl DM, Abbott MR, Bidigare RR. Light driven seasonal patterns of chlorophyll and nitrate in the lower euphotic zone of the North Pacific Subtropical Gyre. Limnol Oceanogr. 2004;49:508-519.

19. Lomas MW, Lipschultz F. Forming the primary nitrite maximum: nitrifiers or phytoplankton? Limnol Oceanogr. 2006;51:2453-2467. 
20. Olson RJ. Differential photoinhibition of marine nitrifying bacteria: a possible mechanism for the formation of the primary nitrite maximum. J Mar Res. 1981;39:227-238.

21. Zakem EJ, Al-Haj A, Church MJ, Dijken GL, Dutkiewicz S, Foster SQ, et al. Ecological control of nitrite in the upper ocean. Nature Commun. 2018;9:1206.

22. Collos Y. Nitrate uptake, nitrite release and uptake, and new production estimates. Mar Ecol Prog Ser. 1998;171:293-301.

23. Laws EA, Wong DCL. Studies of carbon and nitrogen metabolism by three marine phytoplankton species in nitrate-limited continuous culture. J Phycol. 1978;14:406-416.

24. Sciandra A, Amara R. Effects of nitrogen limitation on growth and nitrite excretion rates of the dinoflagellate. Mar Ecol Prog Ser. 1994;105:301-309.

25. Raimbault P. Effect of temperature on nitrite excretion by three marine diatoms during nitrate uptake. Mar Biol. 1986;92:149-155.

26. Serra JL, Llama MJ, Cadenas E. Nitrate utilization by the diatom Skeletonema costatum I. Kinetics of nitrate uptake. Plant Physiol. 1978;62:987-990.

27. Olson RJ, Soohoo JB, Kiefer DA. Steady-state growth of the marine diatom Thalassiosira pseudonana: uncoupled kinetics of nitrate uptake and nitrite production. Plant Physiol. 1980;66:383-389.

28. Collos Y. Transient situations in nitrate assimilation by marine diatoms. 2. Changes in nitrate and nitrite following a nitrate perturbation. Limnol Oceanogr. 1982;27:528-535.

29. Milligan AJ, Harrison PJ. Effects of non-steady-state iron limitation on nitrogen assimilatory enzymes in the marine diatom Thalassiosira weissflogii (Bacillariophyceae). J Phycol. 2000;36:78-86.

30. Martinez R. Transient nitrate uptake and assimilation in Skeletonema costatum cultures subject to nitrate starvation under low irradiance. J Plankton Res. 1991;13:499-512.

31. Cordero OX, Polz MF. Explaining microbial genomic diversity in light of evolutionary ecology. Nat Rev Microbiol. 2014;12:263-273.

32. Kent AG, Baer SE, Mouginot C, Huang JS, Larkin AA, Lomas MW, et al. Parallel phylogeography of Prochlorococcus and Synechococcus. ISME J. 2019;13:430-441. 
33. Heldal M, Scanlan DJ, Norland S, Thingstad F, Mann NH. Elemental composition of single cells of various strains of marine Prochlorococcus and Synechococcus using X-ray microanalysis. Limnol Oceanogr. 2003;48:1732-1743.

34. Biller SJ, Berube PM, Dooley K, Williams M, Satinsky BM, Hackl T, et al. Marine microbial metagenomes sampled across space and time. Sci Data. 2018;5:180176.

35. Kiefer DA, Olson RJ, Holm-Hansen O. Another look at the nitrite and chlorophyll maxima in the central North Pacific. Deep-Sea Res Oceanogr Abstr. 1976;23:1199-1208.

36. Johnson KS, Riser SC, Karl DM. Nitrate supply from deep to near-surface waters of the North Pacific subtropical gyre. Nature. 2010;465:1062-1065.

37. Ritchie RJ. The ammonia transport, retention and futile cycling problem in cyanobacteria. Microb Ecol. 2013;65:180-196.

38. Neijssel OM, Buurman ET, de Mattos MJT. The role of futile cycles in the energetics of bacterial growth. BBA-Bioenergetics. 1990;1018:252-255.

39. Santoro AE, Dupont CL, Richter RA, Craig MT, Carini P, McIlvin MR, et al. Genomic and proteomic characterization of "Candidatus Nitrosopelagicus brevis": an ammoniaoxidizing archaeon from the open ocean. Proc Natl Acad Sci USA. 2015;112:1173-1178.

40. Santoro AE, Casciotti KL. Enrichment and characterization of ammonia-oxidizing archaea from the open ocean: phylogeny, physiology and stable isotope fractionation. ISME J. $2011 ; 5: 1796-1808$.

41. Santoro AE, Saito MA, Goepfert TJ, Lamborg CH, Dupont CL, DiTullio GR. Thaumarchaeal ecotype distributions across the equatorial Pacific Ocean and their potential roles in nitrification and sinking flux attenuation. Limnol Oceanogr. 2017;62:1984-2003.

42. Sintes E, De Corte D, Haberleitner E, Herndl GJ. Geographic distribution of archaeal ammonia oxidizing ecotypes in the Atlantic Ocean. Front Microbiol. 2016;7:77. 